\title{
Impact of Export and Import on 40 years Economic Growth in the Philippines
}

\author{
Liane Vina G. Ocampo, Ph.D. ', Rosario B. Gumban, Ph.D. ', Jessie Anne T. Demetillo Ph.D \\ ${ }^{\text {a }}$ Cavite State University, Philippines \\ ${ }^{\mathrm{b}}$ Cavite State University, Philippines \\ ${ }^{\mathrm{c}}$ Cavite State University, Philippines \\ a lianeocampo@cvsu.edu.ph,brbgumban@cvsu.edu.ph, ${ }^{\mathrm{b} j t d e m e t i l l o @ c v s u . e d u . p h ~}$
}

Article History: Received: 10 November 2020; Revised 12 January 2021 Accepted: 27 January 2021; Published online: 5 April 2021

\begin{abstract}
The Philippine economy, as a newly industrialized country, remained to be resilient and competitive enough to be one of the five growth performers in the region. As the country grows, it faces greater challenges towards its aim for development. Same way as other developing nations, the Philippines still experience a trade deficit. This situation in the economy must take into consideration seeing that the balance of trade is considered as one of the key components in measuring the relative strength of the country's economy.

This research investigates the association between export, imports, and economic growth in the Philippines. The study collected trade balance indicators and economic output for the period of 1978 to 2017. The unit root test was employed to test the presence of unit root at level and first difference. Vector Autoregression analysis was used to the relationship exist among variables. The result determined that the past value of imports have a significant impact on the Economic Output measured in terms of GDP. On the export side, the Wald test statistics showed that the previous values of export jointly could influence the Gross Domestic Output. These results provide evidence that exports and imports can influence economic growth in the Philippines.
\end{abstract}

Keywords: Economic growth, Exports, Trade Balance, Trade Deficit, Imports, Vector Autoregression

\section{Background, Motivation, and Objectives}

The Philippines is facing significant challenges in attaining sustainable and inclusive economic growth at the pace of Globalization. The first globalization period was recorded from 1870 to 1914; it was driven by the invention of steamship and causes international trade flows to increase (Antras, 2020). The extent of integration among countries is continuously increasing since many countries in the world are already open to international trade (Johansson \& Nilsson, 2007). These lead to structural shifts and changes in the dynamics of international trade (Mora, 2014).

To have a significant part in the global economy, meaningful opportunities for developing nations through Global value chains (GVCs). It allows the countries to acquire knowledge and technology, and increase the value of their commodities (UNIDO, 2015). The concept of international boundaries has redrawn (Ponte, 2019 et al.) and generates a strong link between businesses, employees, and consumers around the globe and often opens opportunities to firms and labourers in developing nations to take part in the global economy (Gereffi, FernandezStark, 2016). GVC's is the process where firms import materials to produce commodities for exports and export inputs. These are re-exported further by their trading partners. It also serves as opportunities for international specialization (Hauser, 2017) with a full range of activities undertaken across international borders (Doherty \& Verghese, 2018) which extends the value-chains beyond products and considering the service involvement (Banga, 2013). Another significant dimension in the GVCs is its rising potential that drives sustainability, growth, and productivity (OECD, 2013) that can also reflect a close relationship between the evolution of GVCs and the global trade role on GDP growth (Backer \& Flaig, 2017).

The Philippines is a relative newcomer to GVCs compared to other countries in the ASEAN region. Over the past few decades, the economy of the Philippines is considered an emerging market that transitioned from agriculturally based to the one dependent on services manufacturing (CGGC, 2016). The country faced a negative trade balance being the 37th largest export-oriented economy in the world (Observatory of Economic Complexity, 2017), and this trade deficit can an impact on the economy as a whole. The recorded trade deficit in 2015 was $\$ 23$ billion and which increases to $\$ 35.5$ billion in 2016; and in 2017, the imbalance rose to $\$ 40.5$ billion (Philippine Statistics Authority). Imports are outpacing exports, the actual impact of these trade deficits both in the short run and long run of the country's economic output is still unclear. The result of the study will be beneficial for policymakers as a basis for developing strategies to resolve the potential impact of the trade deficit in the country. 
The purpose of the study is to evaluate the significant correlation of economic growth on export and imports in the Philippines considering these trade variables as components of the value chain. The empirical study of the critical elements of the theoretical hypothesis was done through econometric co-integration analysis and Vector autoregression.

\section{Theoretical Framework}

Theory of comparative advantage. Ricardo emphasized the mutual benefit between countries from international trade.

According to the model, the nation should concentrate and specialize in goods and services where it had a comparative advantage and acquire those products on commodities that do not have a comparative advantage (Manolis, n.d.) The trade theories have assisted the understanding of GVCs (Herr \& Dünhaupt, 2019).

New Trade Theory. The trade model was developed after the 1980s emergence of economies of scale from a new perspective (Schmitz, 2017). This concept emphasized market failures, cost advantages, and economies of scale as influencing forces behind international trade (Medin, 2014) It incorporates innovations on neoclassical economics such as strategic behaviour, politics, market imperfections, industrial economics, and growth theory. (Deraniyagala, Fine, 2001). It considered critical factors of international trade patterns as substantial components of economies of scale.

\section{Statement Of Contribution And Methods}

The research attempts to contribute to the body of knowledge by assessing the macroeconomic variables in relevance to the evolution of trade theories driven by globalization and trade liberalization among countries. The model was formulated through empirical estimation and application of appropriate econometrics tools to provide new insights that could serve as a basis for policy formulation and recommendation.

The result is expected to be useful for future researchers who intents to analyze the imports and export trends in their respective countries.

Data. The researcher utilized secondary data collected through the records of the Philippine Statistics authority online database and on the World Bank website. Data included in the study involves annual data of Gross Domestic Product. Imports and Export (at current US\$) from the year 1978 to 2017.

Methodology. A quantitative methodology was applied to examining the correlation between export, import, and economic growth. Vector Autoregressive Regression analysis was applied in analyzing the significant relationship between variables. The model estimation is considered a powerful tool in examining the dynamic relationships between the indicated time series variables. The mathematical form for the regression is:

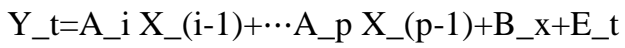

Where:

$\mathrm{Y}$

$$
=\text { dependent variables }
$$

$\mathrm{A} \& \mathrm{~B}$

$$
=\text { Independent variables }
$$

i-1 \& p-1 = lagged values of the variables

$\mathrm{Bx}$

$$
=\text { intercept }
$$

Et

$$
=\text { error terms }
$$

Model Specification. The unit root and co-integration test approaches were utilized in forecasting the estimated Vector Autoregression model. Economic variables are usually non-stationary. It is therefore essential to test for stationary before generalizing any relationship and Augmented Dickey-Fuller test statistic was also utilized to test the variables in the study. In examining the interrelationship between variables in the model, the error variance decomposition estimates and impulse response functions were applied.

The specification of the VAR models can be defined as follows:

$$
\begin{aligned}
& \text { GDP }=\mathrm{f}(\text { Imp, Exp }) \\
& \text { Imp }=\mathrm{f}(\text { GDP, Exp }) \\
& \text { Exp }=\mathrm{f}(\text { GDP, Imp })
\end{aligned}
$$




\section{Results, Discussion, And Conclusion}

This paper collected 40 observations from the annual record ranges of the Philippines from the year 1978 to 2017 to examine the correlation between variables. This section presents the descriptive statistics, unit root tests, Johansen co-integration test forecast error variance decomposition, and impulse response functions.

Descriptive Analysis. Table I shows the summary statistics used in the study. The normality of data was tested using the values of skewness and kurtosis. It indicates a normal curve for all the variables with values ranging between -3 and +3 . On the other hand, the Jacque-bera chi-square showed that only GDP is significant 5 percent level while imports and exports transcend the limit in the paper.

Table I. Summary of Statistics

\begin{tabular}{lrrr}
\hline & IMPORTS & EXPORT & GDP \\
\hline Mean & $42,200,000,000.00$ & $1,600,000,000,000.00$ & $108,000,000,000.00$ \\
Median & $40,600,000,000.00$ & $1,500,000,000,000.00$ & $78,600,000,000.00$ \\
Maximum & $128,000,000,000.00$ & $4,200,000,000,000.00$ & $314,000,000,000.00$ \\
Minimum & $5,660,000,000.00$ & $372,000,000,000.00$ & $22,700,000,000.00$ \\
Std. Dev. & $33,300,000,000.00$ & $1,020,000,000,000.00$ & $90,100,000,000.00$ \\
Skewness & 0.78 & 0.59 & 1.13 \\
Kurtosis & 2.75 & 2.45 & 2.91 \\
\hline Jarque-Bera & 4.13 & 2.87 & 8.59 \\
Probability & 0.13 & 0.24 & 0.01 \\
Observations & 40.00 & 40.00 & 40.00 \\
\hline
\end{tabular}

Unit Root Test. The existence of unit roots in the set of data was assessed using the Augmented Dickey-Fuller test was conducted. The result revealed that the study failed to reject the null hypothesis. It suggests The gross domestic product, import, and export were non-stationary at level.

The variables were observed to be stationary after taking the first difference of the variables. It suggests conducting a lag selection and co-integration test between variables.

Table II. Augmented Dickey-Fuller Test

\begin{tabular}{lllllll}
\hline & AT LEVEL & \multicolumn{5}{c}{ AT 1ST DIFFERENCE } \\
\hline VARIABLE & ADF & P-Value & Decision & ADF T-stat & P-Value & Decision \\
\hline GDP & 1.000000 & 1.0000 & NS & -3.52644 & 0.0125 & $\mathrm{~S}$ \\
& & & & & & \\
EXPORT & 1.206288 & 0.9977 & NS & -6.87264 & 0.0000 & $\mathrm{~S}$ \\
IMPORT & 2.717142 & 1.0000 & NS & -5.17374 & 0.0001 & $\mathrm{~S}$ \\
\hline
\end{tabular}

Lag selection criteria. Lag length criteria using Eviews suggests the optimal lag for the particular. Table 2 illustrates the result of the criteria. The analysis considered the five selection criteria at a 5\% level of significance. The result showed that the majority of the criteria suggested in employing three lags for the VAR, including LR test statistic, Final Predication Error, Akaike and Schwarz, and Hannan-Quinn information criterion. Therefore, the analysis is preceded using three lags. 
Table III. Lag selection Criteria

\begin{tabular}{ccccccc}
\hline Lag & LogL & LR & FPE & AIC & SC & HQ \\
\hline 0 & -2754.72 & NA & $11,000 \ldots$ & 149.0658 & 149.1964 & 149.1118 \\
1 & -2598.6 & 278.4727 & $3,880 \ldots$ & 141.1137 & $41.6361^{*}$ & 141.2979 \\
2 & -2585.83 & 20.72141 & $3,200 \ldots$ & 140.9095 & 141.8238 & 141.2318 \\
3 & -2572.68 & $19.18563^{*}$ & $2,630 \ldots *$ & $140.6854^{*}$ & 141.9915 & $41.1458^{*}$ \\
\hline
\end{tabular}

LR: sequential modified LR test statistic (at 5 percent level)

FPE: Final prediction error

AIC: Akaike information criterion

$S C$ : Schwarz information criterion

HQ:Hannan-Quinn information criterion

* indicates lag order selected by the criterion

Johansen co-integration test. The Co-integration test determines the presence of a long-run relationship among variables. The trace test (Table IV) and Maximum Eigen-value statistics (Table V) confirms the presence of cointegrating equations among variables.

The trace test demonstrates that there is a long-run relationship among variables with no co-integrating equation with a critical value of $29.79707(\mathrm{P}<0.05)$

Another co-integration test was Eigen Value Test implies that there is an association among variables with no co-integrating equation with a critical value of $21.13162(\mathrm{P}<0.05)$.

Table IV. Trace Test

\begin{tabular}{lllll}
\hline Rank & Eigenvalue & Statistic & Critical Value & Prob.** \\
\hline None $*$ & 0.545745 & 43.66279 & 29.79707 & 0.0007 \\
At most 1 & 0.277243 & 15.25529 & 15.49471 & 0.0543 \\
At most 2 & 0.094326 & 3.566735 & 3.841466 & 0.0589 \\
\hline
\end{tabular}

Table V. Maximum Eigen Value Test

\begin{tabular}{llccc}
\hline Rank & Eigenvalue & Statistic & Critical Value & Prob.** \\
\hline None * & 0.545745 & 28.4075 & 21.13162 & 0.004 \\
At most 1 & 0.277243 & 11.68855 & 14.2646 & 0.1229 \\
At most 2 & 0.094326 & 3.566735 & 3.841466 & 0.0589 \\
\hline
\end{tabular}

Granger Causality Test. The empirical result reveals unidirectional causalities between GDP and export, GDP, and Import but no causality between export and import. It indicates that these variables are substantial causal factors of GDP in the Philippines.

Table VI. Granger Causality Test

\begin{tabular}{lcc}
\hline Variables & Nature of Causality & Decision \\
\hline Export and GDP & Unidirectional & Reject Null \\
Import and GDP & Unidirectional & Reject Null \\
Export and Import & No causality & Accept Null \\
\hline
\end{tabular}

Three equations were formed from the VAR Results:

1. $\mathrm{GDP}=1.4387 * \mathrm{GDP}(-1)-1.1893 * \mathrm{GDP}(-2)+0.8509 * \mathrm{GDP}(-3)+2.0373 * \mathrm{EXP}(-1)-1.2997 * \mathrm{EXP}(-2)+$ $1.5714 * \operatorname{EXP}(-3)-2.2378 * \operatorname{IMP}(-1)+2.9414 * \operatorname{IMP}(-2)-2.7619 * \operatorname{IMP}(-3)-1365126877.72$

2. $\mathrm{EXP}=0.2301 * \mathrm{GDP}(-1)-0.4142 * \mathrm{GDP}(-2)+0.1825 * \mathrm{GDP}(-3)+0.7629 * \mathrm{EXP}(-1)-0.8232 * \mathrm{EXP}(-2)+$ $0.6913 * \operatorname{EXP}(-3)-0.2903 * \operatorname{IMP}(-1)+1.4033 * \operatorname{IMP}(-2)-0.7362 * \operatorname{IMP}(-3)+1276320982.95$

3. $\mathrm{IMP}=0.0299 * \mathrm{GDP}(-1)-0.2329(-2)+0.2927(-3)+0.3066 * \mathrm{EXP}(-1)-0.6354 * \mathrm{EXP}(-2)+0.4062 * \mathrm{EXP}(-$ $3)+0.5385 * \operatorname{IMP}(-1)+0.9157 * \operatorname{IMP}(-2)-0.6220 * \operatorname{IMP}(-3)-18289370.2405$ 
Variance Decomposition. Further examination of the dynamic effects of GDP, Import, and export in the Philippines was applied. The rest results for the three variables were obtained, presented, and analyzed in the study.

The variance decomposition of Gross Domestic Output in the table below shows that there is a substantial amount of variation experienced in the GDP, which is attributed to its shock in the first period. The shock follows a decreasing trend to about $72.24 \%$ at the end of the period. On the other hand, the export marginally follows an increasing trend from the first period to the end of the horizon. Import shocks follow a rising trend from the first period to the eighth period but decrease in the succeeding period where it stood at $19.75 \%$.

Table VII. Variance Decomposition of GDP

\begin{tabular}{ccccc}
\hline Period & S.E. & GDP & EXPORTS & IMPORTS \\
\hline 1 & $7,440,000,000.00$ & 100.000000 & - & - \\
2 & $12,700,000,000.00$ & 87.649840 & 0.001497 & 12.348660 \\
3 & $17,000,000,000.00$ & 86.545790 & 0.801017 & 12.653190 \\
4 & $21,300,000,000.00$ & 84.538620 & 2.187465 & 13.273910 \\
5 & $25,600,000,000.00$ & 79.909860 & 3.012786 & 17.077350 \\
6 & $30,000,000,000.00$ & 76.422800 & 3.220867 & 20.356330 \\
7 & $34,600,000,000.00$ & 74.506020 & 3.677950 & 21.816030 \\
8 & $39,400,000,000.00$ & 73.305860 & 4.789132 & 21.905010 \\
9 & $43,800,000,000.00$ & 72.595800 & 6.280953 & 21.123250 \\
10 & $47,600,000,000.00$ & 72.246810 & 7.996496 & 19.756700 \\
\hline
\end{tabular}

In the short run, the impulse or shock to export accounted for a $27.94 \%$ variation on the fluctuation in export (own shock) as shown in the first period but decreased to 20.44 in the last period. The GDP illustrates an increasing trend from the first to third period amounting to 77.88 percent and gradually decrease to 68.24 in the sixth period but increased again to 72.01 percent at the end of the period. Import shocks follow an increasing trend from the first period to the eighth period but decrease in the succeeding period.

Table VIII. Variance Decomposition of Export

\begin{tabular}{|c|c|c|c|c|}
\hline Period & S.E. & GDP & EXPORTS & IMPORTS \\
\hline 1 & $4,580,000,000.00$ & 72.062050 & 27.937950 & - \\
\hline 2 & $5,900,000,000.00$ & 77.933460 & 21.109150 & 0.957394 \\
\hline 3 & $6,990,000,000.00$ & 77.882100 & 19.329480 & 2.788419 \\
\hline 4 & $8,420,000,000.00$ & 71.321780 & 23.257720 & 5.420500 \\
\hline 5 & $9,260,000,000.00$ & 68.606350 & 25.295800 & 6.097848 \\
\hline 6 & $9,850,000,000.00$ & 68.242440 & 24.560510 & 7.197056 \\
\hline 7 & $10,600,000,000.00$ & 68.646010 & 23.314620 & 8.039368 \\
\hline 8 & $11,500,000,000.00$ & 69.404780 & 22.448030 & 8.147197 \\
\hline 9 & $12,300,000,000.00$ & 70.472740 & 21.502960 & 8.024298 \\
\hline 10 & $13,100,000,000.00$ & 72.005320 & 20.442860 & 7.551819 \\
\hline
\end{tabular}

The assessment of variance decomposition of import in table 9 shows that a large amount of the variation on imports is attributed to GDP shocks ranging from 60.90 to $74.15 \%$ within the period. A small amount of the variation experienced on imports is attributed to its shock ranging from 10.12 to 19.04 percent within the time horizon. Meanwhile, exports follow an increasing trend from 18.06 percent in the first period to 20.12 in the fifth. It then decrease to 12.84 percent at the end of the horizon.

Table IX. Variance Decomposition of Import 


\begin{tabular}{rrrrr}
\hline Period & \multicolumn{1}{l}{ S.E. } & GDP & EXPORTS & IMPORTS \\
\hline 1 & $5,140,000,000.00$ & 66.972380 & 18.060520 & 14.967100 \\
2 & $6,690,000,000.00$ & 69.740950 & 18.872820 & 11.386230 \\
3 & $7,830,000,000.00$ & 65.162190 & 19.441120 & 15.396690 \\
4 & $9,020,000,000.00$ & 60.901350 & 20.061120 & 19.037530 \\
5 & $9,830,000,000.00$ & 60.929060 & 20.118850 & 18.952090 \\
6 & $10,600,000,000.00$ & 63.158640 & 18.782860 & 18.058490 \\
7 & $11,400,000,000.00$ & 66.748020 & 17.090500 & 16.161470 \\
8 & $12,500,000,000.00$ & 70.634950 & 15.704310 & 13.660740 \\
9 & $13,600,000,000.00$ & 74.149400 & 14.323790 & 11.526800 \\
10 & $15,000,000,000.00$ & 77.041330 & 12.835460 & 10.123210 \\
\hline
\end{tabular}

Conclusion. This paper determines the correlation between export, imports, and economic output growth in the Philippines. The result concludes that there is a significant association between GDP, Import, and export. Hence, the import and export fluctuations were observed to have caused the change in gross domestic output and vice versa. The increase in inflation rate may lead to a lower gross domestic product, but a higher money supply resulted in a higher gross domestic product.

The result also determined that the past value of imports has a significant impact on the economic output measured in terms of GDP. On the import side, the granger causality test and Wald statistics showed that the previous values of import jointly could influence the Gross Domestic Output. These results provide evidence that exports and import can influence economic growth in the Philippines.

\section{References}

P. Antràs, Conceptual Aspects of Global Value Chains. Retrieved from: https://scholar.harvard.edu/files/antras/files/conceptual_aspects_gvcs.pdf, 2020

K. Backer, D. Flaig, The Future of Global Value Chains Business As Usual Or "A New Normal"? OECD Science, Technology and Innovation Policy Papers No. 41. Organization for Economic Co-operation and Development. Retrieved from: http://www.iberglobal.com/files/2017-2/GVCs-_future_OCDE.pdf, July 2017

S. Deraniyagala, B. Fine, New Trade Theory versus Old Trade Policy: A Continuing Enigma. Cambridge Journal of Economics. 25. 809-25. 10.1093/cje/25.6.809, November 2001

S. Doherty, A. Verghese, System Initiative on Shaping the Future of International Trade0020and Investment. Global Value Chain Policy Series. World Economic Forum, November 2001

G. Gereffi, K. Fernandez-Stark, Global Value Chain Analysis: A Primer. Duke Center on Globalization, Governance \& Competitiveness. Retrieved from: https://www.researchgate.net/profile/Gary_Gereffi/ publication/305719326_

Value_Chain_Analysis_A_Primer_2nd_Edition/links/579b6f0708ae80bf6ea3408f/Global-Value-Chain-

Analysis-A-Primer-2nd-Edition.pdf , July 2016

H. Medin, New trade theory. Implications for industrial policy. Retrieved from: https://www.researchgate.net/publication/281631713_New_trade_theory_Implications_for_industrial_policy, January 2014

H. Herr, P. Dünhaupt, Global Value Chains in economic development, Working Paper, No. 124/2019, Hochschule für Wirtschaft und Recht Berlin, Institute for International Political Economy (IPE), Berlin, 2019

C. Heuser, A. Mattoo. Global Value Chain Report. Services trade and global value chains, 2017

B. Johansson, D. Nilsson, Globalization and Distribution of Exports, CESIS Electronic Working Paper Series, Paper No. 93. Retrieved from: http://www.diva-portal.org/smash/get/diva2:487506/FULLTEXT01.pdf, 2007

Observatory of Economic Complexity Philippines, Retrieved from: https://oec.world/en/profile/country/phl/, 2017

Organization for Economic Co-operation and Development, Interconnected Economies: Benefiting Global Value Chains. Paris,

B. Pfaff, 2008. VAR, SVAR and SVEC models: Implementation within R package vars. Journal of Statistical Software, 27(4): 1-32 Retrieved from: https://doi.org/10.18637/jss.v027.i04

Philippine Statistics Authority, PSA Annual Report 2017

Philippine Statistics Authority, PSA Annual Report 2016

Philippine Statistics Authority, PSA Annual Report 2015

S. Ponte, G. Gereffi, G. Raj-Reichert. Introduction to the Handbook on Global Value Chains. Retrieved from: https://www.researchgate.net/publication/337023208, 2019

S. Manolis, David Ricardo: Life, Original Ideas And The Greek Translations Of His Works, n.d. 
United Nations Industrial Development Organization, Global Value Chains and Development: UNIDO's Support towards Inclusive and Sustainable Industrial Development Center on Globalization, Governance \& Competitiveness, or CGGC (May 2016). The Philippines in Manufacturing Global Value Chains An Introduction. Duke University, 2015

A. Schmitz, Policy and Theory of International Trade. Chapter 6. Economies of Scale and International Trade, December 29, 2012.

\section{Authors Profile}

Liane Vina G. Ocampo is a graduate of Doctor of Philosophy in business management at Philippine Christian University. She is a professor in statistics, business, and economics at Cavite State University Open Learning College and a college instructor of the Entrepreneurship program of Cavite State University, Imus Campus. She has an international publication in a peer-reviewed journal in the field of econometrics and presented several research journals in local and international conferences. She is also affiliated with several academic and professional organizations.

Rosario B. Gumban is a graduate of Doctor of Philosophy in Business Management at Philippine Christian University. She has been into writing and mentoring researches and presented in local and international conferences. She is a professor in Business Management and Graduate School Open Learning College at Cavite State University. She is also affiliated with numerous professional organizations - national and international.

Jessie Anne T. Demetillo is a graduate of Doctor of Philosophy in Business Management at Philippine Christian University, Philippines. She has been engaged in conducting and writing researches related to her field and currently designated as a research services coordinator of Cavite State University - Trece Martires City Campus to where she also works as a professor for more than 10 years now. She is also affiliated with several professional organizations both locally and internationally. 